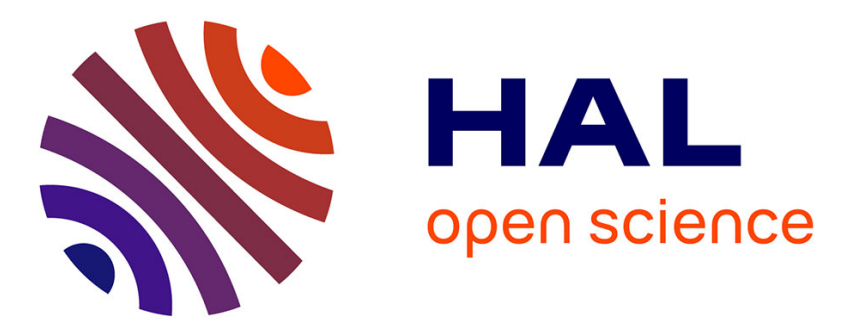

\title{
Low-velocity impact behaviors of repaired CFRP laminates: Effect of impact location and external patch configurations
}

Yuliang Hou, Ying Tie, Cheng Li, Thaneshan Sapanathan, Mohamed Rachik

\section{- To cite this version:}

Yuliang Hou, Ying Tie, Cheng Li, Thaneshan Sapanathan, Mohamed Rachik. Low-velocity impact behaviors of repaired CFRP laminates: Effect of impact location and external patch configurations. Composites Part B: Engineering, 2019, 163, pp.669 - 680. 10.1016/j.compositesb.2018.12.153 . hal03485851

\section{HAL Id: hal-03485851 \\ https://hal.science/hal-03485851}

Submitted on 20 Dec 2021

HAL is a multi-disciplinary open access archive for the deposit and dissemination of scientific research documents, whether they are published or not. The documents may come from teaching and research institutions in France or abroad, or from public or private research centers.
L'archive ouverte pluridisciplinaire HAL, est destinée au dépôt et à la diffusion de documents scientifiques de niveau recherche, publiés ou non, émanant des établissements d'enseignement et de recherche français ou étrangers, des laboratoires publics ou privés.

\section{(c) (1) $\$$}

Distributed under a Creative Commons Attribution - NonCommerciall 4.0 International 


\title{
Low-velocity impact behaviors of repaired CFRP laminates: Effect of impact location and external patch configurations
}

\author{
Yuliang $\mathrm{Hou}^{\mathrm{a}, \mathrm{b}, *}$, Ying Tie ${ }^{\mathrm{a}, *}$, Cheng $\mathrm{Li}^{\mathrm{a}}$, Thaneshan Sapanathan ${ }^{\mathrm{b}, \mathrm{c}}$, Mohamed Rachik ${ }^{\mathrm{b}}$ \\ ${ }^{a}$ School of Mechanical Engineering, Zhengzhou University, Science Road 100, 450001, Zhengzhou,China \\ ${ }^{b}$ Laboratoire Roberval, CNRS UMR7337, Sorbonne université, Université de Technologie de Compiègne, Centre de \\ recherche Royallieu, CS60319, 60203, Compiègne Cedex, France \\ ${ }^{c}$ Institute of Mechanics, Materials and Civil Engineering, UCLouvain, 1348 Louvain-la-Neuve, Belgium
}

\begin{abstract}
Experimental and numerical approaches are used to investigate the effect of impact location and different external patch configurations on the low-velocity impact behaviors of repaired CFRP laminates. Various external patches with different thicknesses (number of layers) and stacking sequences are considered and those patches are used to repair single side of the damaged laminate plates to improve the impact-resistance. To predict the damage initiation and progression of the repaired CFRP laminates under impact loading, a continuum damage mechanics (CDM) model that combines 3D Hashin damage criteria and cohesive zone model (CZM) is proposed. The corresponding drop-weight impact tests are conducted to experimentally obtain the impact response such as impact force and energy. Numerical impact simulations have been performed to study the effect of impact location during the low-velocity impact behaviors of repaired structures. Parametric studies of patch thickness and stacking sequence are also carried out using the low-velocity impact simulation to analyze their effect on the impact-resistance. Finally, this study provides an optimization cafeteria to identify the important design parameter to perform external patch repair based on the simulation results.
\end{abstract}

Keywords: Low-velocity impact, External patch repair, Impact location, Patch thickness, Stacking sequence

\section{Introduction}

Composite materials such as carbon fiber reinforced polymer (CFRP) laminates, are increasingly used in high-performance engineering applications due to their inherently excellent mechanical properties and low specific weight [1-6]. Usually, CFRP laminates are susceptible to the low-velocity impact of foreign objects in service life. Inevitably, partial damages caused by such impact on CFRP laminates lead to the reduction of local mechanical properties. To reduce the maintenance cost, such small impact damages usually require a repairment of the damaged composite structures rather than replacement as the initial solution [7-12]. Therefore, the development

\footnotetext{
${ }^{*}$ Corresponding author.

Email addresses: yulianghou@zzu.edu.cn (Yuliang Hou), tieying@zzu.edu .cn (Ying Tie)
} 
of external patch repair techniques is in high demand to overcome this engineering issue and to deliver an improved mechanical performance at a reduced cost.

Commonly, composite patches are manufactured and locally bonded to the damaged regions to recover the impact-resistance of the damaged structures. Moreover, research and development in the subject of repair performance mainly focuses on the bonding process and the patch design [1315]. Hence, a properly bonded well-designed patch to a damaged composite structure can recover its mechanical performance as close as its original condition (i.e. a composite structure without any damage). Despite of these advantages, the repair process introduces a few inherent features and it significantly reduces the integrity and stability of the repaired structures. One of the main concern which limits the application of the external patch repair for high performance components of composite structures is the poor load carrying capacity during a low-velocity impact [10, 1618]. However, the repair technique with external patches has been widely used in the industrial applications since it is relatively convenient and economically viable.

In general, the repaired composite structures with external patches are still susceptible to other low-velocity impact of foreign objects during regular maintenance and in service life. Due to the poor impact resistance of the repaired structures and the cohesion between patch and parent materials, the impact damage often occurs around the bonding interface [17, 18]. For CFRP laminates, matrix cracking, fiber breakage, delamination and debonding are the four principal damage mechanisms during an impact [19-21]. Especially, when a foreign object strikes a laminate, the matrix cracking and delamination are the most common damage mechanisms. Meanwhile, shock waves are generated within the laminates and the repaired structures encounter a very high impact energy $[15,22,23]$. Therefore, the sources to absorb the impact energy and to decrease the delamination area around the repaired region are important factors for composite structures, and they significantly affect the damage behaviors during the impact.

In an external patch design, one should consider a combination of parameters that includes fiber/matrix interface strength, mechanical properties of fiber, patch thickness, stacking sequence, patch shape etc. Each parameter has its own influence on the final repair performance. An optimal patch design can be obtained using both numerical and experimental approaches which consider the aforementioned parameters. In the study of Andrew et al. [23, 24], repaired glass/epoxy laminates with external patches and unrepaired structures were investigated with repeated low-velocity impacts. They compared the impact response and identified that the repaired laminates had significantly enhanced capability to resist a large number of impacts. Moreover, they adopted different hybrid external patches which were manufactured using plain weave woven glass fabric and aluminum alloy to repair composite laminates. Low-velocity impact tests had been performed on the repaired and undamaged composite laminates. Their experimental results indicated that the hybrid and hand lay-up configurations of the external patches improved the impact resistance. The specimens repaired with external patches with outer layer of aluminum and inner layer of glass fiber possessed better load carrying capacity than the composites repaired with pure glass fiber patches. Coelhe et al. [16] experimentally investigated the impact fatigue behaviors of composite laminates repaired using various external bonded patches with different patch configurations. Among all their patch designs, higher impact resistance was obtained for the double-patch configuration.

Numerical approaches are also used to predict the low-velocity impact behaviors and failure of the repaired specimens with external patches [17, 25-31]. Cheng et al. [25, 26] investigated the 
tensile behavior of patch-repaired CFRP laminates using numerical modeling, and proposed an optimization method of bonded patch repair by introducing a strength ratio, which was computed using Hoffman failure criteria. By minimizing the strength ratio, optimal repair patch parameters were identified. An optimal repair patch can restore more than $90 \%$ of the tensile strength of the initial material. Tie et al. [17] established a finite element (FE) model for the specimens repaired with various single patch designs based on a continuum damage mechanics (CDM) principle [32]. Different patch shapes and sizes were considered in their simulation of low-velocity impact tests. Based on the prediction of absorbed energy and delamination area of each case, the circle patch with the radius of 2.5 times of the damage hole was identified to offer the optimum repair performance.

In the present study, circular holes are considered as the damage source, that have been cut on different locations of parent CFRP laminates using water-jet machine to manufacture the damaged specimens. Then, single-side circle patches with various thicknesses and stacking sequences are used to repair these damaged specimens. Influence of external patch design parameters and impact location on the low-velocity impact behavior of the repaired CFRP laminates has been investigated using experimental and numerical approaches.

The structure of the paper is organized in the following manner: Section 2 introduces the experimental procedure; Section 3 briefly describes the FE simulation; Section 4 presents the adopted CDM method based on 3D Hashin criteria and cohesive zone model (CZM); Section 5 includes the validation procedure of the numerical simulation, analyses on the influence of impact location on the low-velocity behaviors, and a discussion on the repairing effect of various patch design parameters on repair performance; Section 5 also proposes an optimization design strategy of external repair patch, and finally the paper ends with conclusions.

\section{Experimental procedure}

\subsection{Materials and specimen preparation}

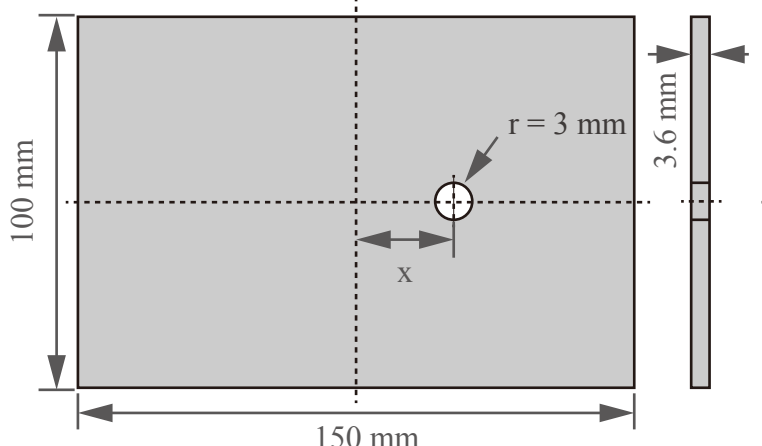

(a)

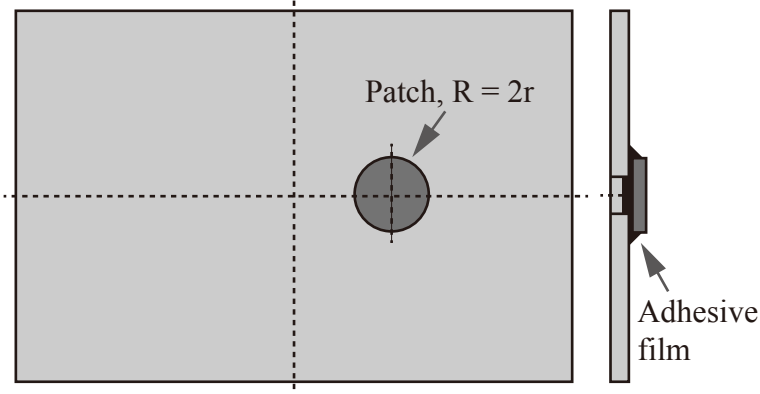

(b)

Figure 1: Geometry information of: (a) damaged and (b) patch-repaired CFRP laminates.

CFRP laminates with the dimension of $150 \mathrm{~mm} \times 100 \mathrm{~mm} \times 3.6 \mathrm{~mm}$, composed of T300 carbon fiber and 7901 resin, were used as the parent plates. The laminates had the stacking sequence of $\left[(0 / 90)_{3}\right]_{S}$. Circular holes with the radius of $r=3 \mathrm{~mm}$ were cut at different locations of these 
parent plates using water jet cutting, which were considered as the accidentally caused local damages. The damage holes were set at $20 \mathrm{~mm}$ and $30 \mathrm{~mm}$ distances (correspond to the distance $\mathrm{x}$ in Fig. 1a) to the center of parent plates while the center of the plates were defined as the impact point. The dimensions of the damaged laminates are given in Fig. 1(a).

Table 1: Mechanical properties of materials.

\begin{tabular}{llll}
\hline Properties & T300/7901 & Properties & LJM-200 \\
\hline$E_{1}(\mathrm{GPa})$ & 125 & $E(\mathrm{GPa})$ & 3.40 \\
$E_{2}, E_{3}(\mathrm{GPa})$ & 11.30 & $v$ & 0.35 \\
$v_{12}$ & 0.30 & $X(\mathrm{MPa})$ & 50 \\
$v_{23}$ & 0.42 & $Y, Z(\mathrm{MPa})$ & 94 \\
$v_{13}$ & 0.30 & & \\
$G_{12}, G_{13}(\mathrm{GPa})$ & 5.43 & & \\
$G_{23}(\mathrm{GPa})$ & 3.98 & & \\
$X_{t}(\mathrm{MPa})$ & 2000 & & \\
$X_{c}(\mathrm{MPa})$ & 1100 & & \\
$Y_{t}, Z_{t}(\mathrm{MPa})$ & 80 & \\
$Y_{c}, Z_{c}(\mathrm{MPa})$ & 280 & & \\
$S(\mathrm{MPa})$ & 120 & & \\
$G_{I C}^{t}(\mathrm{~N} / \mathrm{mm})$ & 0.52 & & \\
$G_{I C}^{c}(\mathrm{~N} / \mathrm{mm})$ & 0.92 & & \\
\hline
\end{tabular}

In our experimental test plan, the damaged laminates were repaired using single circular patches, which were manufactured from the same CFRP laminates but with different stacking sequence of [0/90/0]. Patch radius and thickness are $6 \mathrm{~mm}(R=2 r)$ and $0.45 \mathrm{~mm}$, respectively. The schematic illustration of the repaired laminates with the patch is shown in Fig. 1b. During the repair procedure, the damage hole was initially filled with LJM-200 adhesive film whose thickness is $0.12 \mathrm{~mm}$. Subsequently, circular patches were bonded to the specimens (Fig. 1b). Mechanical properties of the composite laminates and adhesive are given in Table 1, where $E$ and $G$ refer to Young's and shear modulus respectively, and $v$ is Poisson's ratio. Subscripts 1, 2, 3 correspond to the longitudinal and two transverse directions, respectively. $X, Y, Z$ and $S$ are longitudinal, transverse, vertical and shear strength, subscripts $t$ and $c$ denote tension and compression, respectively.

\subsection{Low-velocity impact test}

Low-velocity impact tests were carried out using WLJ300 drop-weight testing machine according to the ASTM D7136/D7136-07 standard [33]. Further details of the test conditions are shown in Fig. 2. A hemispherical impactor with diameter of $50 \mathrm{~mm}$ and mass of $2.5 \mathrm{~kg}$ was released from a height of $0.54 \mathrm{~m}$ to the center of the repaired specimen. As shown in Fig. 2, the repaired specimens was placed over a flat support fixture that has a $125 \times 75 \mathrm{~mm}$ rectangular cut-out. Prior to the impact, the repaired specimen was fastened on the support fixture using four rubber clamps. The fixture loading caused by the rubber clamps probably introduces an initial stress field within the repaired specimen. However, this initial stress is relatively smaller than that 
caused by the impact loading, thus it provides a negligible influence on the impact response during the process of low-velocity impact test. Therefore, the initial stress was not considered in this study. Moreover, the cut-out on the fixture enables the impactor to collide the specimen without interferences, and an anti-impact device was used over the fixture to avoid secondary impact on the repaired specimen. Just before the impact, it is assumed that there is no energy loss caused by friction, so that the initial impact velocity $v_{0}$ and energy $E_{k 0}$ are calculated as $3.25 \mathrm{~m} / \mathrm{s}$ and $13.2 \mathrm{~J}$, respectively.

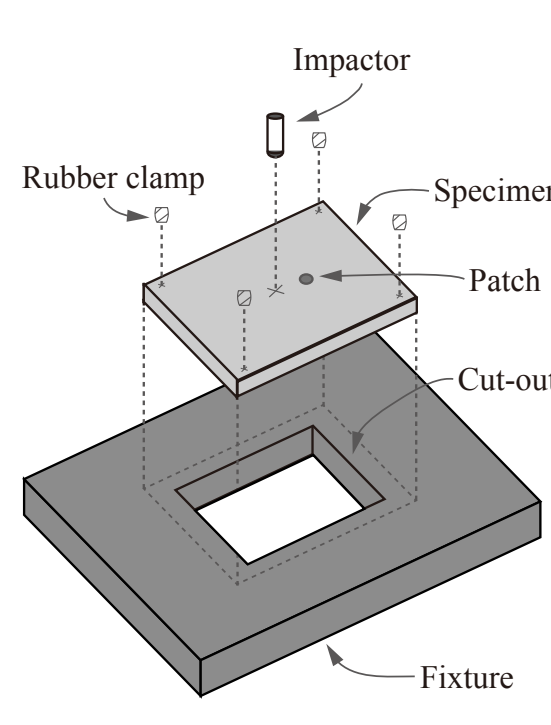

(a)

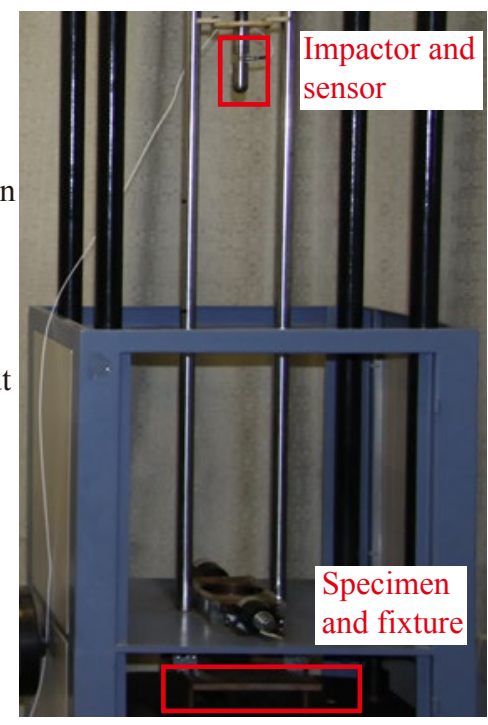

(b)

Figure 2: (a) Schematic illustration of the drop-weight impact test system and (b) the experimental setup used to test the low-velocity impact behaviors of the patch-repaired CFRP laminates .

The instantaneous impact force was measured using a dynamic force sensor (ICP 208C03) during the tests. For each test, the onset of impact is defined by the sudden increase of impact force according to the force-time curve $F(t)$. And, the peak impact force was reached before the impactor penetrated the repaired specimen.

Additionally, the delamination surface area and absorbed energy of each repaired specimen were measured and considered as the parameters to evaluate the repair performance of different patch design configurations. The delamination surface of each specimen was initially characterized by the marked outline, as illustrated in Fig. 8. Then, a transparent paper with uniform grids was placed on the specimen, and the corresponding area was computed by counting the overlapping grids which coincide with the marked delamination surface. Moreover, the history curve of the absorbed impact energy by the specimen $E_{a}(t)$ was calculated using the force-time curve $F(t)$ given by:

$$
E_{a}(t)=E_{k 0}-E_{k}(t)=E_{k 0}-\frac{1}{2} m\left[v_{0}-\frac{1}{m} \int_{0}^{t} F(t) \mathrm{d} t\right]^{2}
$$

where $m$ and $E_{k}(t)$ refer to the mass and transient kinematic energy of the impactor. The final absorbed energy $E_{a}$ is obtained when the converged value appears within the history curve. Three 
patch-repaired specimens for each case were tested to ensure the reproducibility of the results. The variations in these measured impact energy curves are about $1.5 \%$ for each configuration of the repaired specimens. Furthermore, to analyze the repair effect of each patch design, a group of unrepaired specimens (i.e. parent laminates) were also tested.

\section{Finite element simulation}

Numerical modeling was considered to further understand the effect of patch design parameters (particularly patch thickness and stacking sequence) on the repair performance of composite laminates under low-velocity impact. For this purpose, 3D FE models are constructed for both damaged and repaired specimens within Abaqus/Explicit software [34]. Firstly, the experimental cases (Section 2.2) with circular patches containing three plies and the stacking sequence of $[0 / 90 / 0] \mathrm{s}$ were considered to validate the numerical model. Then the validated model was used to determine the best patch design configuration that provides the improved repair performance using a detailed analysis of design parameters.

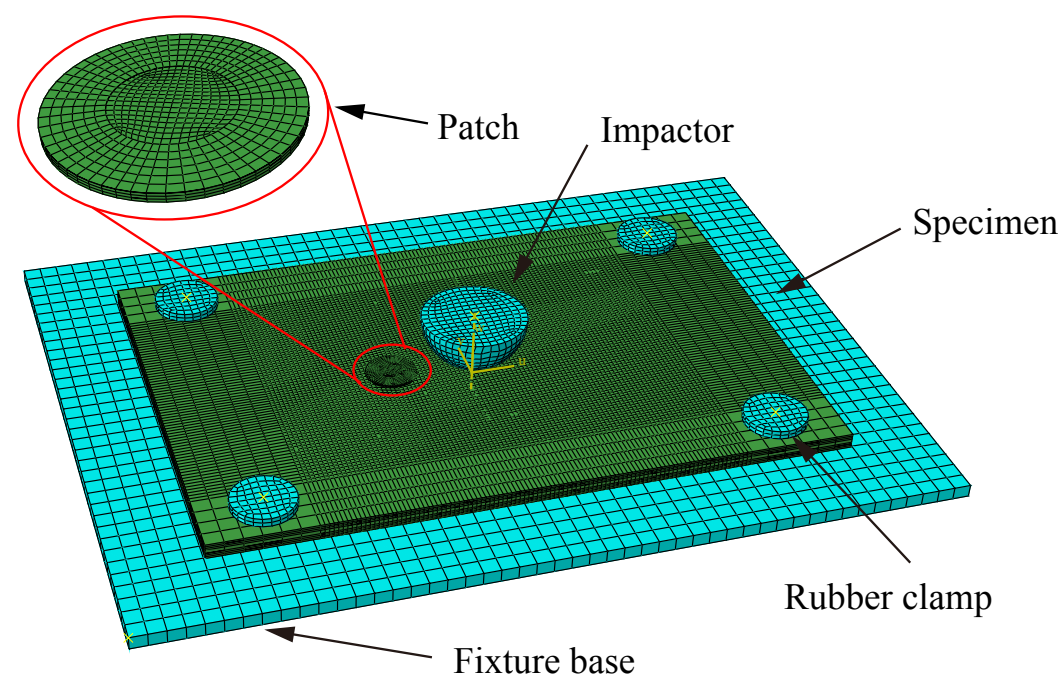

Figure 3: Meshed FE model used for the low-velocity impact test showing a case of repaired specimen with a circular patch.

Fig. 3 shows the meshed FE model used for low-velocity impact simulation which includes a repaired specimen having a circular patch. Eight-node 3D solid, reduced integration elements (element type in Abaqus: C3D8R [34]) were used to mesh the specimen and related component of the test. Moreover, a set of cohesive elements (element type: COH3D8 [34]) were used to describe the adhesive interface between the parent plate and the patch. To ensure the accuracy of the FE simulation, the parent plate and patch are respectively discretized with 65239 and 3331 elements, since they require to be sufficiently fine to capture the damage behaviors caused by the low-velocity impact.

Appropriate boundary conditions are prescribed by fixing all DOFs (degree of freedom) of the fixture and rubber clamps. Although an initial stress field is caused by the fixture loading within the repaired specimen, the influence on the impact response is relatively limited during 
the low-velocity impact test. Hence, the initial stress was not taken into account in the numerical simulation. The impactor is assigned with an initial velocity of $3.25 \mathrm{~m} / \mathrm{s}$ in the vertical direction. During the simulation, it impacts on different locations of the damaged and repaired specimens. From the simulation results, the effect of distance between the repair patch and impact point on the damage behavior is analyzed.

\section{Constitutive models}

In general, damage of composite laminates is classified into two main types: intra-laminar and inter-laminar damage. The intra-laminar damage presents fiber breakages and matrix cracking, while the inter-laminar damage is mainly contributed by delamination and debonding [14]. Therefore, constitutive models used in this study consider both intra- and inter- laminar damage models to effectively capture all possible damage behaviors those occur in a CFRP laminates under low-velocity impact conditions.

\subsection{Intra-laminar damage}

3D Hashin damage criteria $[35,36]$ has been used to predict the intra-laminar damage initiation and the progressive failure of the patch repaired composite laminates. Furthermore, the residual strength of damaged laminates is computed using a continuum damage model (CDM). The corresponding damage evolution using $\mathrm{CDM}$ is adopted after the first appearance of intra-laminar damage.

\subsubsection{D Hashin damage criteria}

3D Hashin damage criteria have been successfully used in numerous FE simulations to predict the intra-laminar damage within composite layers. These criteria consider four individual damages: tensile and compressive damage of both fiber and matrix [37]. And, each damage is governed by the component of the stress tensor associated with the damage plane described by a quadratic equation, as written in Eqs. (2-5).

Fiber tensile damage $\left(\sigma_{11} \geq 0\right)$ :

$$
\left(\frac{\sigma_{11}}{X_{T}}\right)^{2}+\frac{\sigma_{12}^{2}+\sigma_{13}^{2}}{S^{2}} \geq 1
$$

Fiber compressive damage $\left(\sigma_{11} \leq 0\right)$ :

$$
\left(\frac{\sigma_{11}}{X_{C}}\right)^{2} \geq 1
$$

Matrix tensile damage $\left(\sigma_{22}+\sigma_{33} \geq 0\right)$ :

$$
\frac{\left(\sigma_{22}+\sigma_{33}\right)^{2}}{Y_{T}^{2}}+\frac{\sigma_{12}^{2}+\sigma_{13}^{2}+\sigma_{23}^{2}-\sigma_{22} \sigma_{33}}{S^{2}} \geq 1
$$


Matrix compressive damage $\left(\sigma_{22}+\sigma_{33} \leq 0\right)$ :

$$
\left[\left(\frac{Y_{C}}{2 S}\right)^{2}-1\right] \frac{\left(\sigma_{22}+\sigma_{33}\right)}{Y_{C}}+\frac{\sigma_{12}^{2}+\sigma_{13}^{2}+\sigma_{23}^{2}}{S^{2}}+\frac{\sigma_{22}^{2}+\sigma_{33}^{2}}{2 S^{2}} \geq 1
$$

where, $\sigma_{i j}$ are components of stress tensor, while the corresponding stress terms of the composite material are listed in Table 1. Once intra-laminar damage in composite laminates or repair patches has been identified using the damage criteria expressed in Eqs. (2-5), the stiffness matrix $\boldsymbol{C}$ corresponding to the FE equilibrium strain state to the stress must be updated at that particular analysis time step. Then, the constitutive relation of the composite laminates is degraded by the material property degradation model (MDM) by following the detection of damaged elements in any of those four possible damage modes.

\subsubsection{Damage evolution law}

In this study, the CDM effective stress theory has been used by defining the continuous degradation damage variable $D_{f}$ [38], whose value increases with the growth of microscopic damage. Once the damage appears, the constitutive relation of a composite material is expressed as:

$$
\boldsymbol{\sigma}=\frac{\partial W^{e}}{\partial \boldsymbol{\varepsilon}}=\left(1-D_{f}\right) \boldsymbol{C}: \boldsymbol{\varepsilon}
$$

where, $\sigma$ and $\varepsilon$ represent stress and strain tensors, $\boldsymbol{C}$ is the 4 th order stiffness tensor. The value of $D_{f}$ varies from 0 to 1 , which corresponds to the primitive and damaged material states, respectively. Moreover, $D_{f}$ is computed based on 3D Hashin damage criteria and the stress state in each element according to Eq. (7):

$$
D_{f}=1-\left(1-d_{f t}\right)\left(1-d_{f c}\right)
$$

where,

$$
\begin{aligned}
& d_{f t}\left(\varepsilon_{11}\right)=\frac{\varepsilon_{f, 1}^{t}}{\varepsilon_{f, 1}^{t}-\varepsilon_{0,1}^{t}}\left(1-\frac{\varepsilon_{0,1}^{t}}{\varepsilon_{11}}\right) \\
& d_{f c}\left(\varepsilon_{11}\right)=\frac{\varepsilon_{f, 1}^{c}}{\varepsilon_{f, 1}^{c}-\varepsilon_{0,1}^{c}}\left(1-\frac{\varepsilon_{0,1}^{c}}{\varepsilon_{11}}\right)
\end{aligned}
$$

The notations $t$ and $c$ refer the tension and compression, respectively. $\varepsilon_{0,1}^{t}$ and $\varepsilon_{0,1}^{c}$ correspond to the critical tensile and compressive strains when the damage initiates, $\varepsilon_{f, 1}^{t}$ and $\varepsilon_{f, 1}^{c}$ are the maximum strains in tension and compression at the onset of final failure. The maximum failure strains $\varepsilon_{f, 1}^{t}$ and $\varepsilon_{f, 1}^{c}$ are computed by Eq. (10) and Eq. (11), respectively.

$$
\begin{aligned}
\varepsilon_{f, 1}^{t} & =\frac{2 G_{I C}^{t}}{X_{T} L} \\
\varepsilon_{f, 1}^{c} & =\frac{2 G_{I C}^{c}}{X_{C} L}
\end{aligned}
$$


where, $X_{T}$ and $X_{C}$ are respectively the tensile and compressive strengths in fiber direction, $G_{I C}^{t}$ and $G_{I C}^{c}$ are the intra-laminar damage toughness in fiber under tension and compression (given in Table 1), $L$ is the characteristic length of an element used in the FE model of composite laminates.

In addition, once damage occurs in certain elements, the loading capability of the damaged elements is redistributed within other surrounding undamaged elements. Thus, the residual strength of the damaged elements is defined by:

$$
E_{i}^{D}=\left(1-D_{f}\right) E_{i}, \quad G_{i j}^{D}=\left(1-D_{f}\right) E_{i j}, \quad v_{i j}^{D}=\left(1-D_{f}\right) v_{i j}
$$

where, $E_{i}^{D}, G_{i j}^{D}$ and $v_{i j}^{D}$ respectively denote the effective Young's modulus, shear modulus and Poisson's ratio of the material after damage. Correspondingly, $E_{i}, G_{i j}$ and $v_{i j}$ are Young's modulus, shear modulus and Poisson's ratio of material at the primitive state.

To describe the intra-laminar damage behavior of the composite materials, 3D Hashin criteria has been implemented in Abaqus/Explicit [34] using a VUMAT user subroutine. This subroutine includes the damage criteria, damage evolution law and an element deletion criterion. At the individual loading step, the stress state at each integration point in the composite laminates is computed using this user subroutine. Then, the damage criteria are used to determine whether any damage occurs or not within the element, and the elastic properties at that element must be degraded according to the damage mode. A degradation procedure has been introduced into the user subroutine to reproduce the damage in the material. Moreover, when an element is identified to be damaged based on the failure criteria, its stiffness is reduced. After progressive damage calculation, the final damaged elements do not contribute to the strength of the composite laminates or patch, but they enable the rapid convergence during the simulation.

\subsection{Inter-laminar damage}

Cohesive zone model (CZM) [39] is used to describe the delamination between different layers of composite laminates as well as the debonding between damaged laminates and repair patches. The CZM method follows a traction-separation law, in which the traction stress and separation displacement of the nodes on the surfaces are used to determine the initiation of the inter-laminar damage. Moreover, following sections provide the detail of the corresponding damage criteria and evolution law.

\subsubsection{Damage criteria of CZM method}

The interaction area of two adjacent layers and the adhesive interface between damaged laminates and repair patches, can be considered as matrix materials. Hence, the inter-laminar damage behavior is regarded to be linear elastic before the presence of delamination and debonding. Moreover, the traction stress on an interaction surface is composed of a normal traction and two shear tractions [39]. The elastic behavior is given by:

$$
\boldsymbol{t}=\left[\begin{array}{c}
t_{n} \\
t_{s} \\
t_{t}
\end{array}\right]=\left[\begin{array}{ccc}
C_{n} & 0 & 0 \\
0 & C_{s} & 0 \\
0 & 0 & C_{t}
\end{array}\right]\left[\begin{array}{c}
\delta_{n} \\
\delta_{s} \\
\delta_{t}
\end{array}\right]
$$


where, $\boldsymbol{t}$ is the traction stress vector, $\boldsymbol{\delta}$ is the separation displacement vector. And, the subscripts of interaction stiffness $C$ represent three directions that correspond to the three fracture modes (mode I - III), as shown in Fig. 4a-c, respectively.

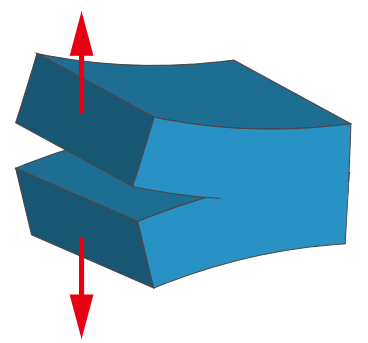

(a) Mode I

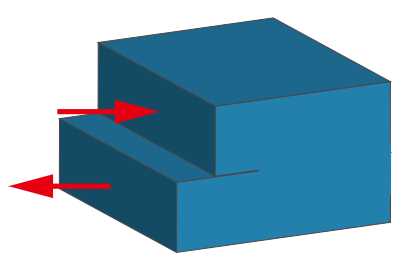

(b) Mode II

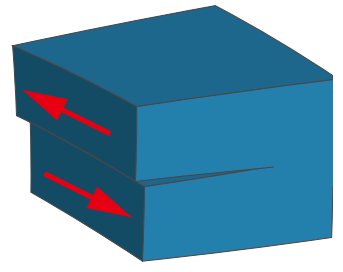

(c) Mode III

Figure 4: Three fracture modes for delamination: (a) normal tension, (b) in-plane (first) shear and (c) out-of-plane (second) shear.

The inter-laminar damage within the repaired laminates is governed by a quadratic separation law [40]. In this law, delamination and debonding appear when the quadratic interaction function reaches 1 , which is given by:

$$
\left(\frac{\left\langle\delta_{n}\right\rangle}{\delta_{n}^{0}}\right)^{2}+\left(\frac{\delta_{s}}{\delta_{s}^{0}}\right)^{2}+\left(\frac{\delta_{t}}{\delta_{t}^{0}}\right)^{2} \geq 1
$$

where, $\delta_{n}^{0}, \delta_{s}^{0}$ and $\delta_{t}^{0}$ denote the peak values of the contact separation, when the separation is either purely along the contact normal or purely in the first or the second shear direction, respectively. An effective separation $\delta_{m}$ is introduced by Eq. (15), which considers normal and shear separations across the cohesive interface.

$$
\delta_{m}=\sqrt{\left\langle\delta_{n}\right\rangle^{2}+\delta_{s}^{2}+\delta_{t}^{2}}
$$

\subsubsection{Damage evolution law}

Similar to the intra-laminar damage, the damage evolution law of inter-laminar damage is divided into two steps, as shown in Fig. 5. Before the appearance of delamination and debonding, the interaction is regarded to possess a linear elastic behavior (Step 1 in Fig. 5). Once the damage criteria in Eq. (14) is satisfied, the cohesive stiffness degrades linearly (Step 2 in Fig. 5).

In Fig. 5, $G^{C}$ denotes the fracture energy of delamination and debonding with mixed modes, in which normal and shear separations appear at the same time. It is formulated based on the Benzeggagh-Kenane fracture criterion as expressed in Eq. (16):

$$
G^{C}=G_{n}^{C}+\left(G_{s}^{C}-G_{n}^{C}\right)\left(\frac{G_{s}^{C}+G_{t}^{C}}{G_{s}^{C}+G_{n}^{C}}\right)^{\eta}
$$

where, $G_{n}^{C}, G_{s}^{C}$ and $G_{t}^{C}$ represent critical values of fracture energy required to cause failure in the normal, the first and the second shear directions, respectively. And, $\eta$ denotes a cohesive property parameter, the value of 1.45 is adopted in the following simulations. The CZM approach has been also integrated and implemented in Abaqus/Explicit framework [34] to predict the interlaminar damage behavior of the interaction between different layers of composite laminates and 


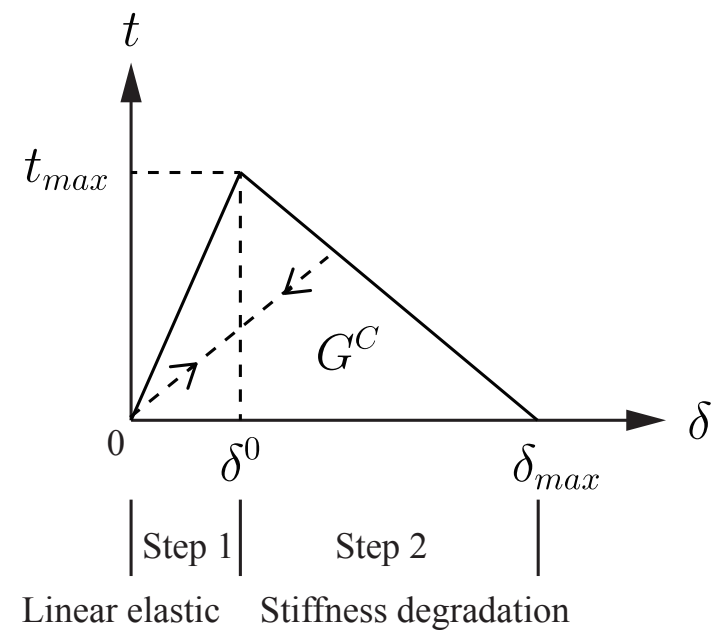

Figure 5: Traction-separation law for the used CZM method.

the bondline between the damaged laminates and repair patches.

\section{Results and discussion}

The effect of the impact location on the damage behaviors of patch repaired laminates is firstly discussed based on experimental and numerical results. Meanwhile, the numerical simulation strategy is validated via the comparison between these results. Then, the effect of external patch parameters (patch thickness and stacking sequence) on the repair performance is investigated using numerical simulation. Finally, optimization of the external patch configuration has been performed based on the simulation.

\subsection{Effect of impact location on the damage behavior of repaired laminates}

To investigate the effect of impact location on the damage behaviors of patch repaired laminates, two methods are possible. The first approach is considered with a configuration that maintains the same impactor's dropping point, while varying the position of damage hole on the parent plate. In contrary, the second approach is considered with varying the impactor's dropping point and fixing the position of damage hole. Concerning the low-velocity impact test described in Section 2.2, the first method has been employed by changing the relative distance $x$ between the damage hole and the impact point on the repaired laminates (see Fig. 1a).

As presented in our experimental plan, two groups of repaired specimens have been prepared with varying relative distance $x(20 \mathrm{~mm}$ and $30 \mathrm{~mm})$. Low-velocity impact tests were performed on these repaired specimens, and impact response in terms of impact force and energy were measured. Moreover, five different relative distances including $0 \mathrm{~mm}, 10 \mathrm{~mm}, 20 \mathrm{~mm}, 30 \mathrm{~mm}, 40 \mathrm{~mm}$ and 50 $\mathrm{mm}$, are considered in the numerical simulation. In the five cases of FE models, the circle patch design same as the experimental cases is adopted. The predicted and experimental impact force and energy history curves of repaired specimens with relative distance $x$ of $20 \mathrm{~mm}$ and $30 \mathrm{~mm}$ from the damage hole to the impact point are illustrated in Fig. 6 and 7, respectively. 


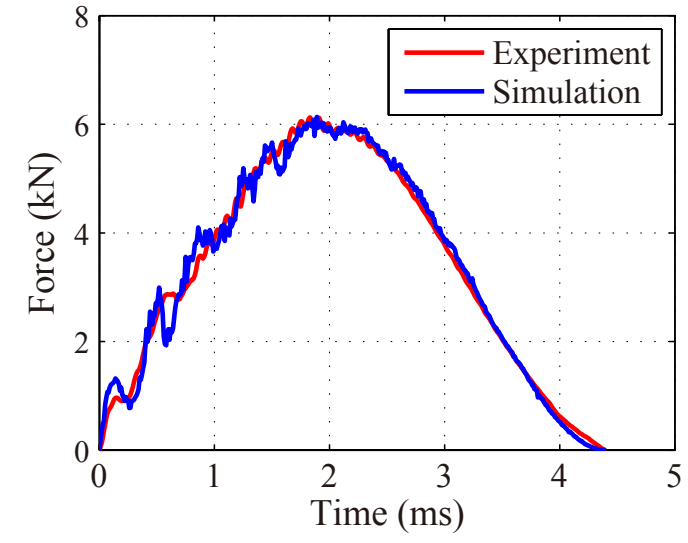

(a)

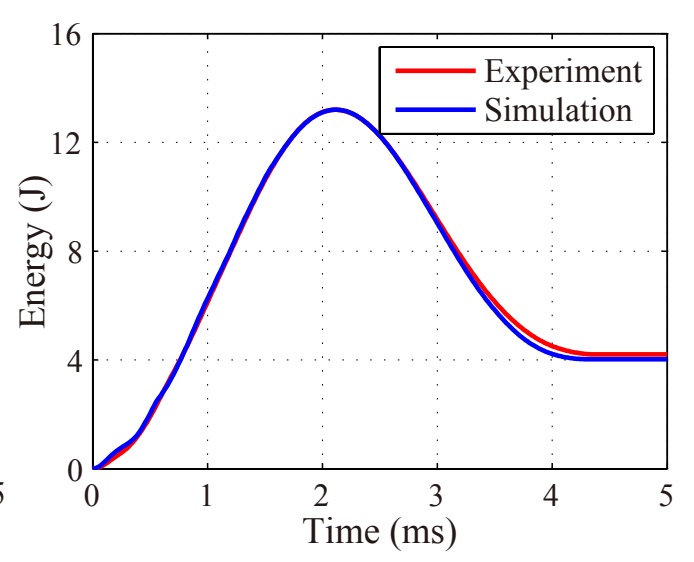

(b)

Figure 6: Measured and predicted (a) impact force and (b) energy history curves of the patch repaired specimens with the relative distance of $x=20 \mathrm{~mm}$ between the damage hole and the impact point.

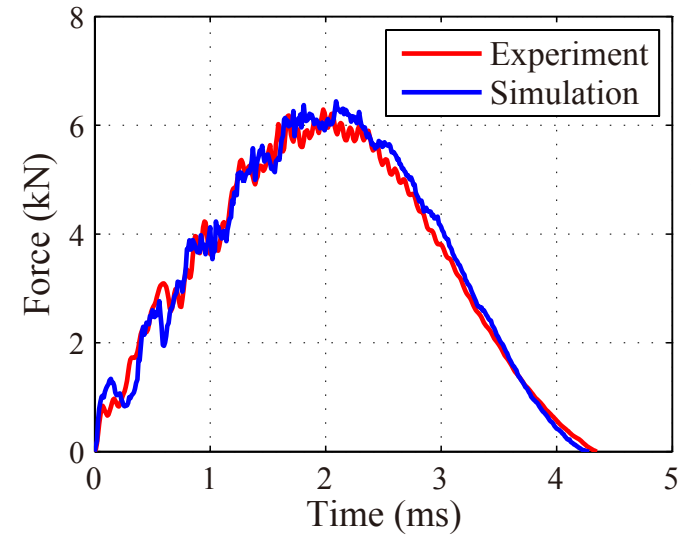

(a)

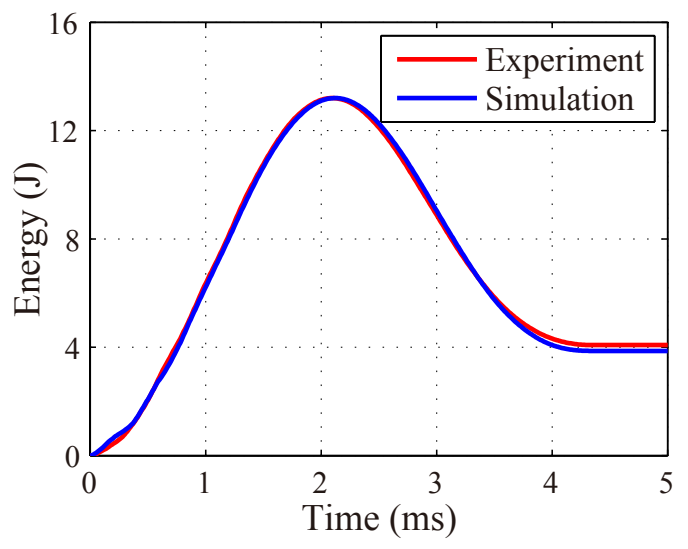

(b)

Figure 7: Measured and predicted (a) impact force and (b) energy history curves of patch repaired specimens with the relative distance of $x=30 \mathrm{~mm}$ between the damage hole and the impact point.

From Fig. 6a and 7a, it is found that, for the relative distance of $x=20 \mathrm{~mm}$, the measured impact force peak reaches the maximum of $6124.2 \mathrm{~N}$ while the predicted maximum force is 6135.4 N. Moreover, in the case of the relative distance $x=30 \mathrm{~mm}$, the measured and predicted impact force peaks appear at $6288.3 \mathrm{~N}$ and $6440.2 \mathrm{~N}$, respectively. Hence, slight discrepancies less than $0.18 \%$ and $2.4 \%$ are found in this comparison between the experimental and predicted maximum impact force. Moreover, the time locus corresponding to the maximum force also agrees well in comparison between experimental and numerical cases for both relative distances. The history curves of impact energy in Fig. $6 \mathrm{~b}$ and $7 \mathrm{~b}$ also indicate that, almost no difference exists for the maximum impact energy and its time locus for both experimental and numerical cases.

Delamination surface area in each case has been also measured from experimental and numerical results to further study the reliability of the used numerical simulation method, as shown in Fig. 8. In this figure, since the bottom view of the experimental results shows the damage more clearly, the delamination surface area (the region marked with white outline in Fig. 8) has been 


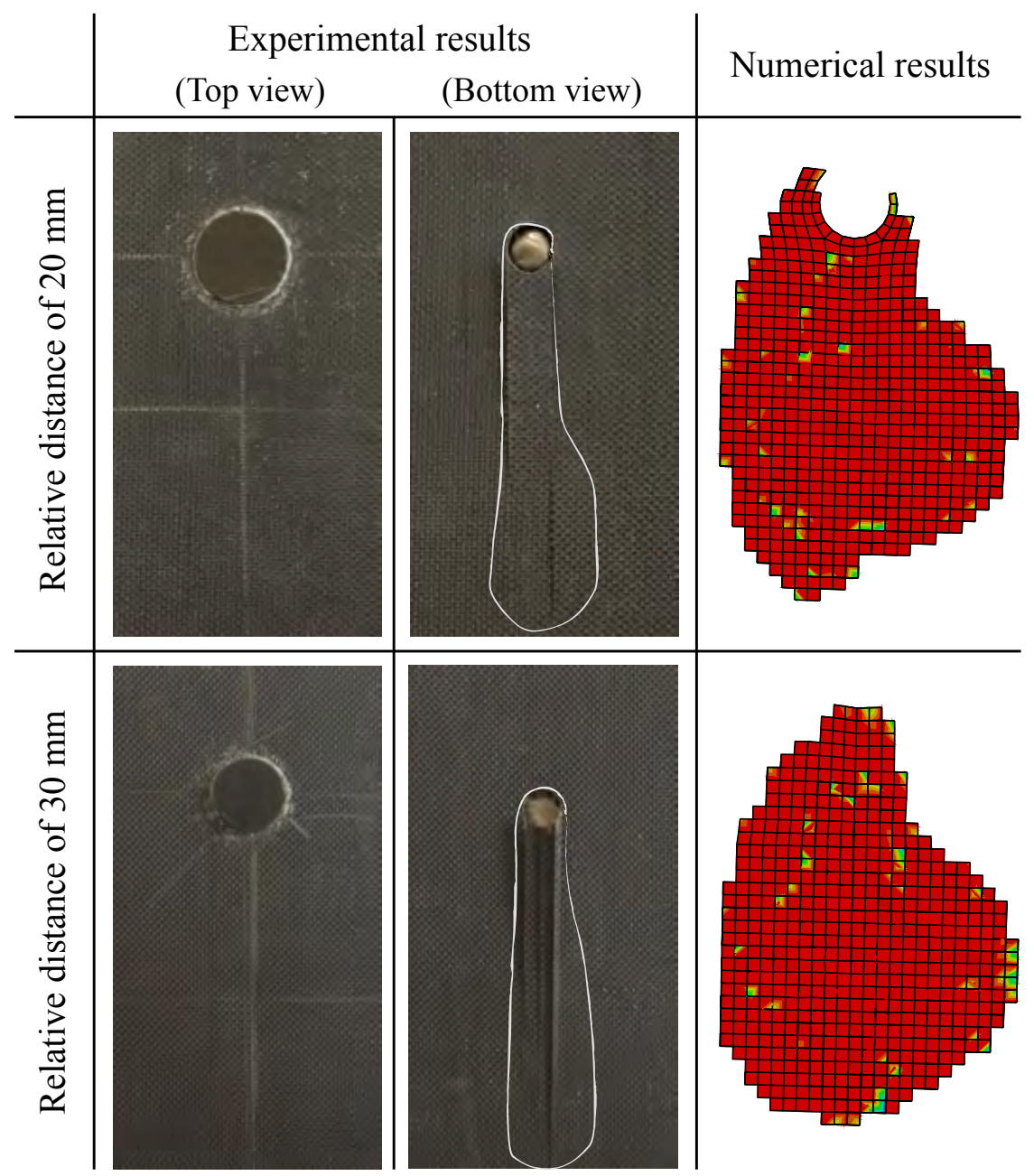

Figure 8: Delamination surface obtained from experimental and numerical low-velocity impact tests.

measured from each specimen's back side (i.e. opposite side to the impactor). Meanwhile, the delamination surface of each specimen is computed by counting the deleted cohesive elements during numerical simulation. During the experiments, the delamination surface areas are approximately $558 \mathrm{~mm}^{2}$ and $536 \mathrm{~mm}^{2}$ for the repaired specimens with relative distances of $20 \mathrm{~mm}$ and 30 $\mathrm{mm}$, respectively. While, the numerical simulations predict $579 \mathrm{~mm}^{2}$ and $522 \mathrm{~mm}^{2}$ respectively corresponding to those two experimental cases. The difference between the experimental and numerical cases are $3.80 \%$ and $2.70 \%$, respectively for the relative distances of $20 \mathrm{~mm}$ and $30 \mathrm{~mm}$. Hence, the predicted delamination areas closely resemble the experimental measurements. Together with the impact response (impact force and energy), it is evidenced that the used numerical simulation strategy is reliable to investigate the low-velocity impact behaviors of patch repaired composites.

The effect of impact location on the damage behavior has been further investigated based on the numerical predictions. Fig. 9 and 10 illustrate the predicted impact force and energy curves of repaired specimens with various relative distances between the damage hole and the impact point 


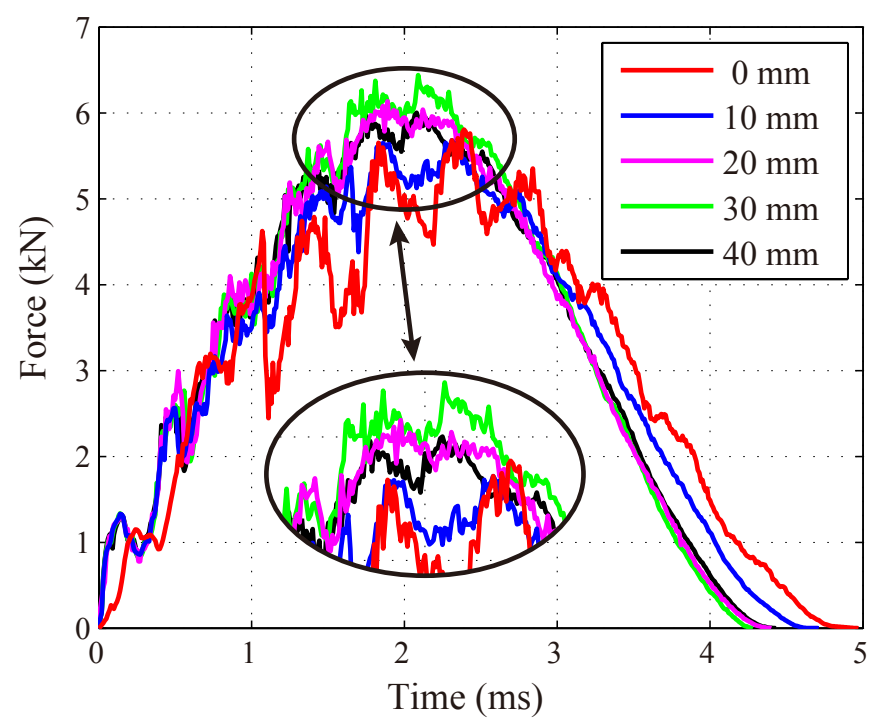

Figure 9: Predicted impact force curves of the patch repaired specimens with different relative distances between the damage hole and the impact point.

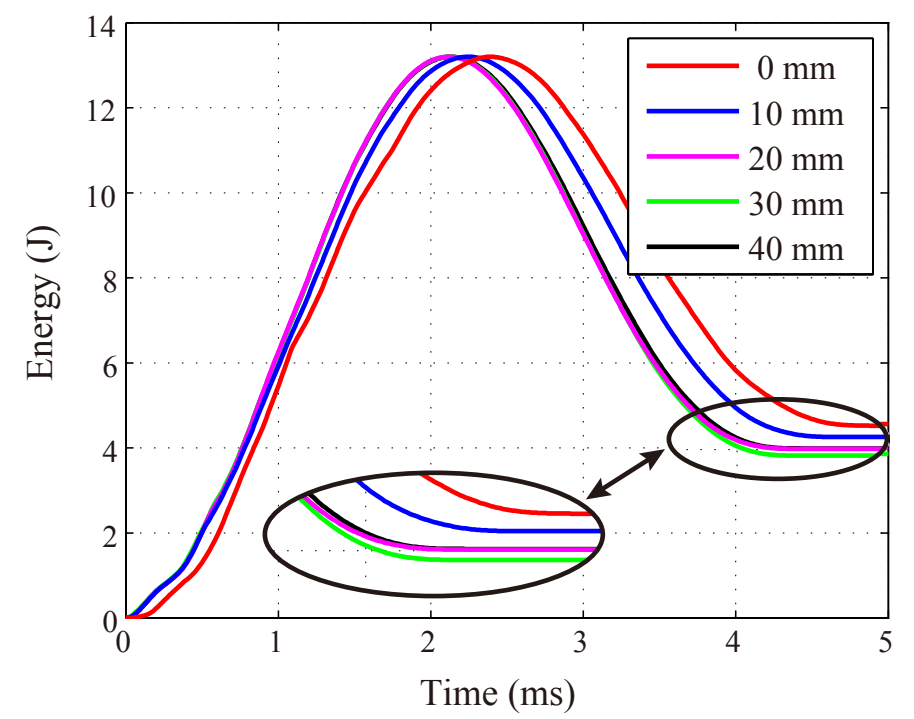

Figure 10: Predicted impact energy curves of the patch repaired specimens with different relative distances between the damage hole and the impact point.

(i.e. the center of parent laminates). Fig. 9 shows that a fluctuation of impact force occurs with a comparable trend during each impact test. The impact force predictions also indicate that the onset of damage for each specimen appears almost on the same location of the history curves. Moreover, by analyzing the fluctuation magnitude of these curves, it can be found that: the maximum force variation appears in the case that the impact point overlaps on the damage hole, while the minimum force variation is observed for the specimen with relative distance of $30 \mathrm{~mm}$. As discussed in literature [17], more fiercely the impact force fluctuates, more impact energy is absorbed by the repaired specimen. Therefore, the repaired specimen with relative distance of $0 \mathrm{~mm}$, absorbs 
highest impact energy than others.

Table 2: Numerical results of repaired specimens with different relative distances.

\begin{tabular}{cccc}
\hline Relative distance $(\mathrm{mm})$ & Force peak $(\mathrm{N})$ & Absorbed energy $(\mathrm{J})$ & Delamination area $\left(\mathrm{mm}^{2}\right)$ \\
\hline 0 & 5805.3 & 4.56 & 553 \\
10 & 5680.0 & 4.30 & 453 \\
20 & 6135.4 & 4.02 & 579 \\
30 & 6440.2 & 3.86 & 522 \\
40 & 6002.7 & 4.03 & 533 \\
\hline
\end{tabular}

In comparison of the predicted impact energy curves, it confirms that the repaired specimen with relative distance of $0 \mathrm{~mm}$ absorbs the maximum energy (i.e. area under the red solid line in Fig. 10). The minimum absorbed impact energy by the repaired specimen case corresponds to the relative distance of $30 \mathrm{~mm}$ (i.e. area under the green solid line). Detailed results of force peak, absorbed energy and delamination area for all the simulation cases are listed in Table 2. Moreover, the correlation between the impact location and damage behaviors depicted in Fig. 11 shows that the absorbed energy decreases with the increase of relative distance from $0 \mathrm{~mm}$ until the case of $30 \mathrm{~mm}$, then passing the $30 \mathrm{~mm}$ distance the absorbed energy tends to increase again. However, the delamination area initially decreases with the increase of relative distance from $0 \mathrm{~mm}$ to 10 $\mathrm{mm}$. After that, a sudden growth appears when the relative distance comes to $20 \mathrm{~mm}$. Then, the delamination area stabilizes at the relative distance of $30 \mathrm{~mm}$.

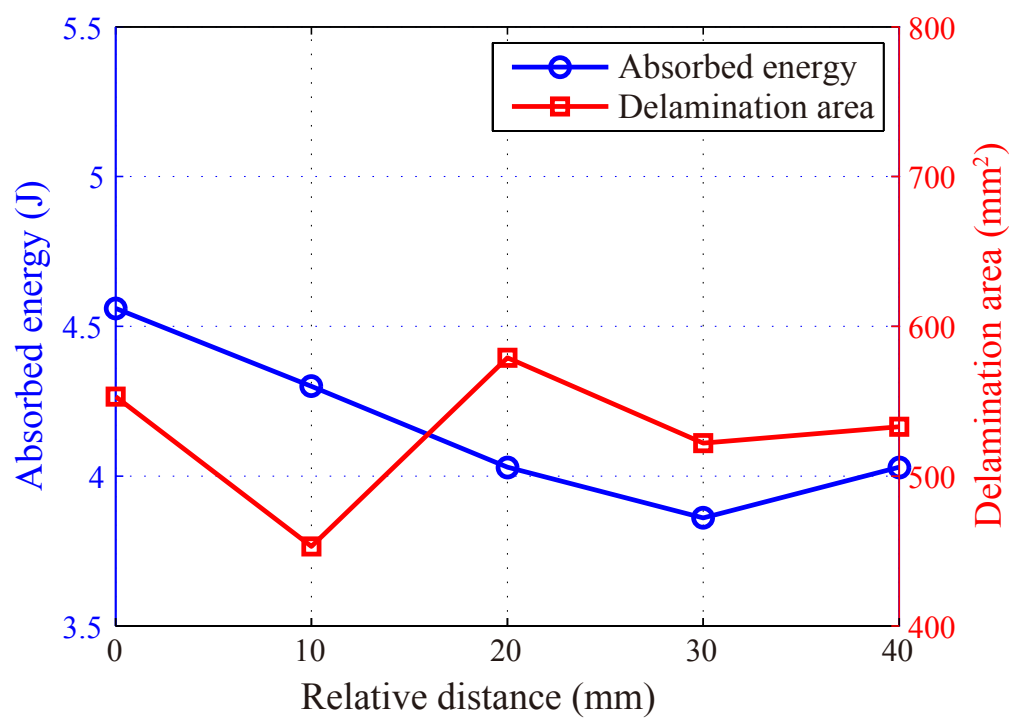

Figure 11: Absorbed energy and delamination surface area curves of specimens repaired with different relative distances.

The difference is mainly caused when the impact point overlaps the damage hole, the impactor firstly penetrates through the patch. This penetration dissipates a large amount of energy during 


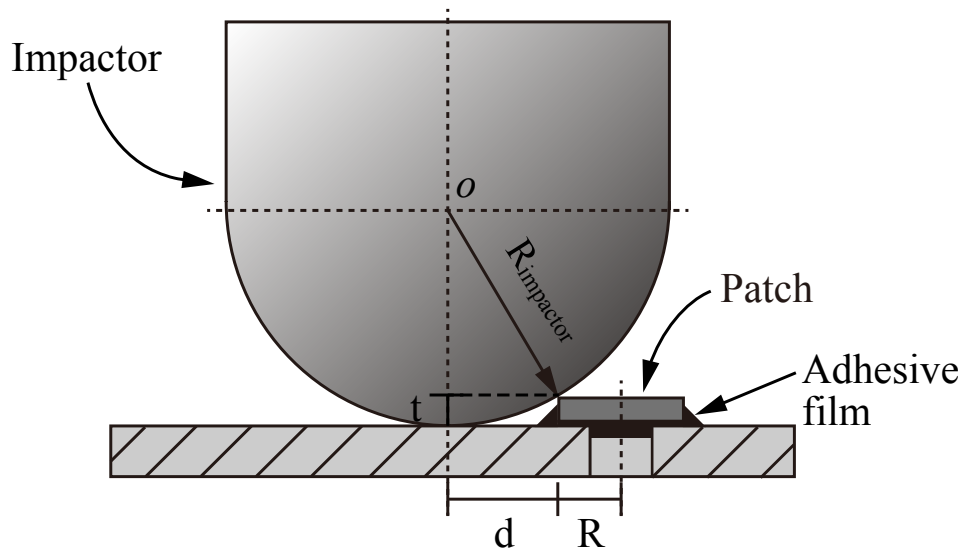

Figure 12: Schematic illustration of the computation of the critical relative distance between the impact point and the damage hole.

the impact, thus it leads to the maximum absorbed energy. During the progression of impact penetration through the patch and the damage hole, the impactor continues to contact and to cause delamination on the parent plate. In the case of the relative distance $x=10 \mathrm{~mm}$, the impactor initially contacts the patch boundary, but it does not penetrate through the patch, thus the delamination and debonding are caused only within the patch. Then, the impactor with an intermediate velocity, which is lower than the maximum value, contacts the parent plate and causes a relatively smaller delamination area. As shown in Fig. 12, the critical value of relative distance $\left(L_{\text {critical }}\right)$ for the appearance of this phenomenon is given by:

$$
L_{\text {critical }}=R+d=2 r+\left[R_{\text {impactor }}^{2}-\left(R_{\text {impactor }}-t\right)^{2}\right]^{1 / 2}
$$

where $t$ is the total thickness of the patch and adhesive film, and its value is $0.57 \mathrm{~mm}$. $d$ denotes the shortest distance between the center of the impact point and the periphery of the patch. From the computation of Eq. (17), the critical relative distance is obtained as $11.308 \mathrm{~mm}$. Moreover, as the relative distance increase to $20 \mathrm{~mm}\left(L>L_{\text {critical }}\right)$, the impactor directly impacts on the parent plate. Thus, it leads to a sudden rise of the delamination area on the repaired specimen. However, relatively less impact energy is absorbed by the repaired structure compared to the previous two cases. When the relative distance exceeds $30 \mathrm{~mm}$, the influence of impact location on the damage behaviors of repaired laminates tends to be feeble. Hence, in order to investigate the effect of patch design parameters on the repair performance, the relative distance of $20 \mathrm{~mm}$ is used in the following numerical simulations.

\subsection{Effect of patch design parameters on the repair performance}

Since the numerical simulation strategy is validated, the effect of external patch design parameters on the repair performance, which include the thickness and stacking sequence of the patch, is investigated using the numerical simulations of low-velocity impact tests. 


\subsubsection{Effect of patch thickness}

The patch thickness mainly depends on the number of layers, so that the effect of patch thickness on repair performance is studied by varying the number of layers. To avoid the influence of other parameters on the repair performance, circle patches are prepared with the same radius. And, plies of $0^{\circ}$ and $90^{\circ}$ are sequentially stacked to produce these patches. Numerical simulations of low-velocity impact tests have been performed on a set of specimens which are repaired using patches with layer number varying from 1 to 5 . Since each ply is $0.15 \mathrm{~mm}$ thick, the total thickness of the patches are $0.15 \mathrm{~mm}, 0.30 \mathrm{~mm}, 0.45 \mathrm{~mm}, 0.60 \mathrm{~mm}$ and $0.75 \mathrm{~mm}$, respectively.

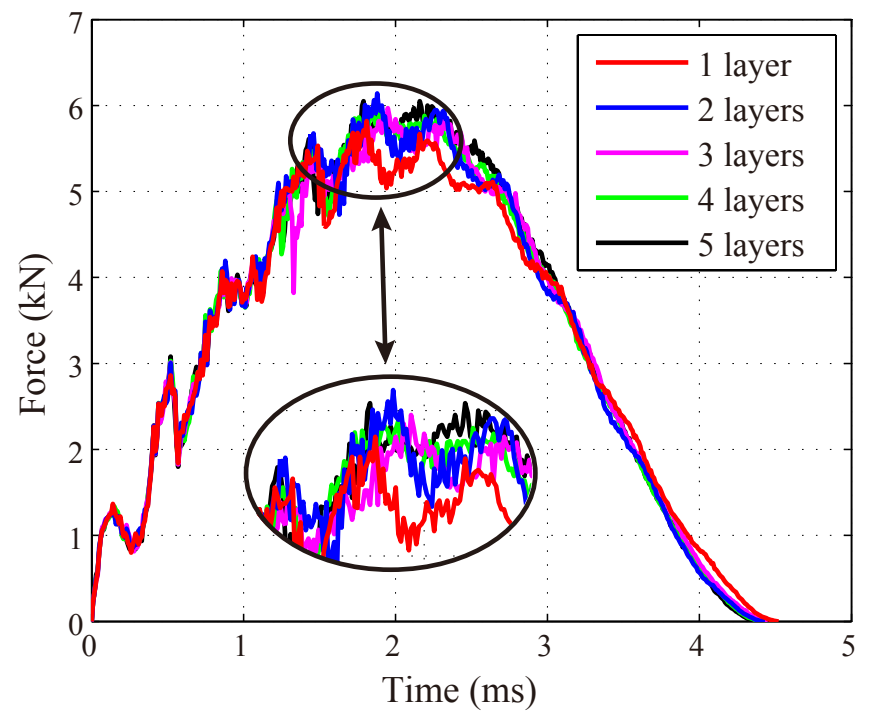

Figure 13: Predicted impact force curves of the repaired specimens using patches with different thicknesses.

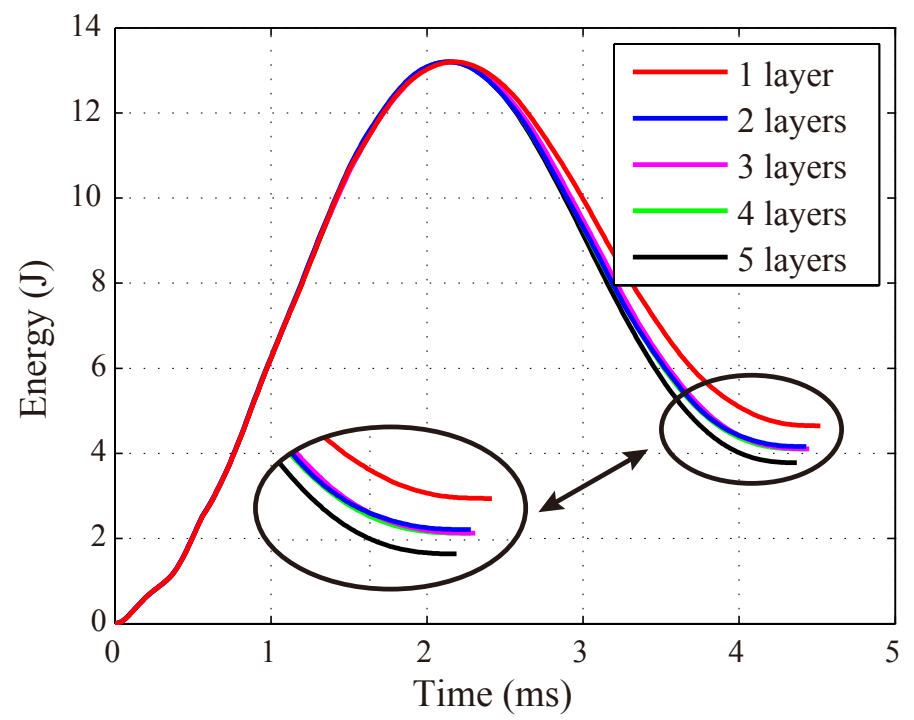

Figure 14: Predicted impact energy curves of the repaired specimens using patches with different thicknesses. 
Table 3: Numerical results of the repaired specimens using patches with different thicknesses.

\begin{tabular}{cccc}
\hline Layer number & Force peak $(\mathrm{N})$ & Absorbed energy $(\mathrm{J})$ & Delamination area $\left(\mathrm{mm}^{2}\right)$ \\
\hline 1 & 5816.6 & 4.65 & 595 \\
2 & 6140.0 & 4.16 & 556 \\
3 & 6135.4 & 4.02 & 579 \\
4 & 6933.3 & 4.10 & 564 \\
5 & 6049.8 & 3.78 & 487 \\
\hline
\end{tabular}

Accordingly, history curves of impact force and energy are predicted as shown in Fig. 13 and 14, respectively. From the comparison in Fig. 13, the significant fluctuation of impact force appears for the case of single-layer patch (i.e. patch thickness of $0.15 \mathrm{~mm}$ ), while no obvious dissimilarity is observed in other cases. Similar fluctuation behaviors are also observed in comparison of the results in Fig. 14. The specimen repaired with single-layer patch absorbs the highest energy during the impact. That is, the most significant damage due to the low-velocity impact occurs when the single layer is adopted in the patch design. Furthermore, as layer number increasing, the damage caused by the impact becomes relatively lower.

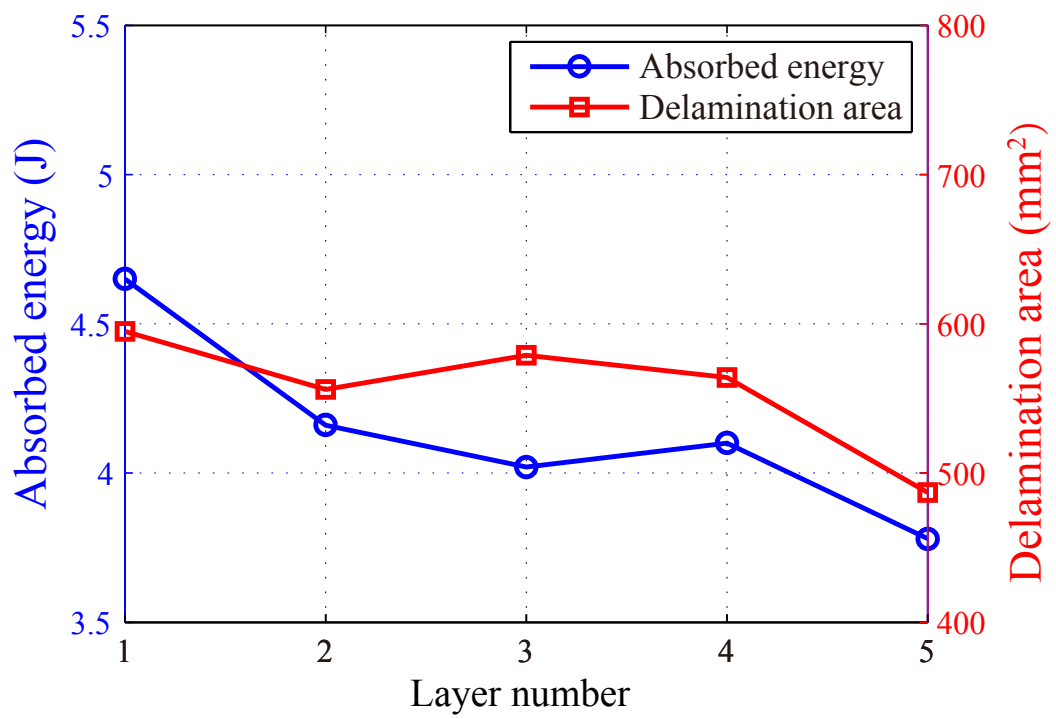

Figure 15: Absorbed energy and delamination surface area curves of the repaired specimens with different patch thicknesses.

Detailed simulation results of specimens repaired using patches with various thickness are listed in Table 3. The correlation between patch thickness against both absorbed energy and delamination area is also depicted in Fig. 15. It can be clearly seen that, the increase in the number of layers presents a decrease in both absorbed energy and delamination area. In other words, better impact-resistance is achievable using thicker patch design. However, if the patch is composed of too many layers, it will introduce singularities on the repaired structures which could affect its static and dynamic properties. The patch design which consists of more than 5 layers (total 
thickness is more than $0.75 \mathrm{~mm}$ ), should not be considered in practical engineering applications. Therefore, we can conclude that, a thicker patch design (until a certain level of thickness) can enhance the impact-resistance of damaged CFRP laminates. A patch with the reasonable thickness (or number of layers) is also required to ensure the mechanical stability of the repaired structure.

\subsubsection{Effect of patch stacking sequence}

In this section, numerical simulations of low-velocity impact tests have been performed on repaired specimens with different patch stacking sequences. To investigate the effect of stacking sequences of the patch in a simplified way, only two kinds of layers with the deposited carbon fiber in the directions of $0^{\circ}$ and $90^{\circ}$, are considered. As discussed in Section 5.2.1, a reasonable thickness should be adopted not only to guarantee the impact-resistance but also to reflect the influence of stacking sequence, three-layer design has been used for each patch design. Four different stacking sequences, including [0/0/0], [0/90/0], [90/0/90] and [90/90/90], are used to construct the repair patches, as shown in Fig. 16. In this figure, the red strip denotes the fiber reinforcement. In the case of fiber orientation parallel to the $\mathrm{X}$ direction (longitudinal direction of the parent plate), the corresponding layer is deposited in $0^{\circ}$ direction. Otherwise, the relative layer direction is $90^{\circ}$.

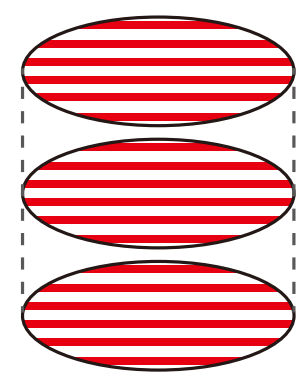

(a)

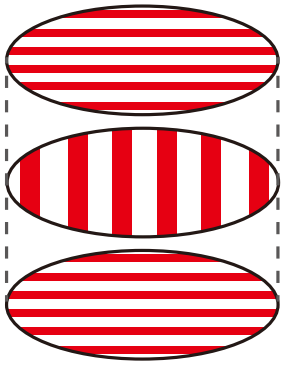

(b)

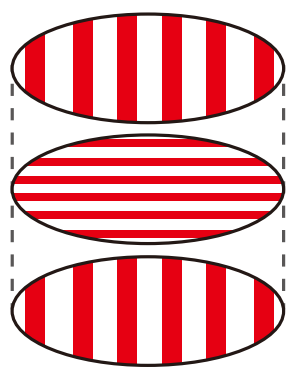

(c)

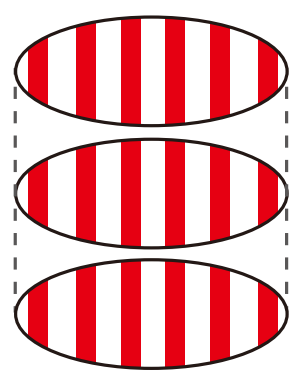

(d)
Fiber $x$ direction

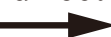

Figure 16: Schematic illustration of patches with different stacking sequences: (a) [0/0/0], (b) [0/90/0], (c) [90/0/90] and (d) $[90 / 90 / 90]$.

Numerical simulations of low-velocity impact tests have been performed on those four designs with different stacking sequences. Fig. 17 and 18 show the predicted impact force and energy curves from the simulations, respectively. From Fig. 17, the largest force fluctuation, in which the force peak is $6122.2 \mathrm{~N}$, appears in the repaired specimens with patch layouts of [90/0/90]. Otherwise, for other specimens, the force fluctuation is approximately same. Moreover, from Fig. 18, the absorbed energies of these four specimens are obtained as $4.11 \mathrm{~J}, 4.46 \mathrm{~J}, 4.02 \mathrm{~J}$ and $3.59 \mathrm{~J}$, respectively. It clearly indicates that, the specimens repaired using latitude-fiber-orientation patch layout are likely to absorb less impact energy than those repaired using mixed-fiber-orientation and longitude-fiber-orientation patch layouts.

Additionally, detailed impact force, absorbed energy and delamination area are listed in Table 4. From the comparison of delamination area, the lowest damage appears within the specimen repaired using the patch with the stacking sequence of [90/90/90]. The corresponding delamination area is $503 \mathrm{~mm}^{2}$, that is $7.4 \%, 15.1 \%$ and $5.0 \%$ lower than the other three repaired specimens with the stacking sequences of [0/0/0], [0/90/0], [90/0/90], respectively. It is also in a good 


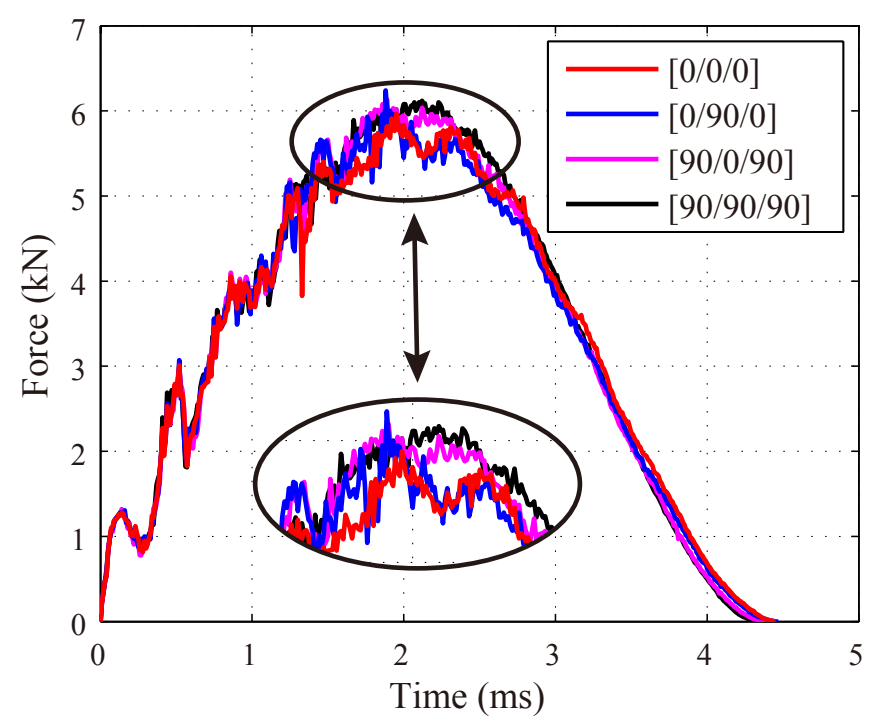

Figure 17: Predicted impact force curves of the repaired specimens with different stacking sequences of the patch.

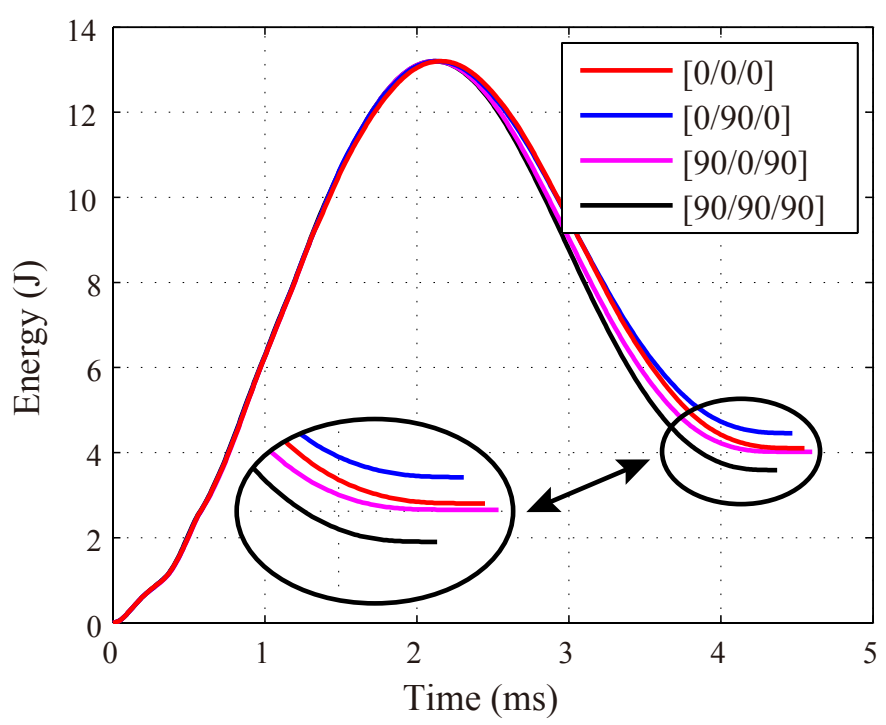

Figure 18: Predicted impact energy curves of the repaired specimens with different stacking sequences of the patch.

Table 4: Numerical results of the repaired specimens using patches with different stacking sequences.

\begin{tabular}{cccc}
\hline Stacking sequence & Force peak $(\mathrm{N})$ & Absorbed energy $(\mathrm{J})$ & Delamination area $\left(\mathrm{mm}^{2}\right)$ \\
\hline$[0 / 0 / 0]$ & 5968.2 & 4.11 & 540 \\
{$[0 / 90 / 0]$} & 6237.4 & 4.46 & 579 \\
{$[90 / 0 / 90]$} & 6135.4 & 4.02 & 528 \\
{$[90 / 90 / 90]$} & 6122.2 & 3.59 & 503 \\
\hline
\end{tabular}

agreement with the comparison of absorbed energy. It means that, the patch design of [90/90/90] 
provides relatively better repair performance than other designs. This is probably because that, the latitude and longitude fiber layers in the repair patch play a significant role to improve the impactresistance of the parent plate with respect to the relative location of the impact point. Although the damage hole weakens the fiber reinforcement in both longitude and latitude directions, the length of parent plate $(150 \mathrm{~mm})$ is relatively larger than the width $(100 \mathrm{~mm})$. Thus, the impact-resistance of the parent plate in the latitude direction is lower than that in the longitude direction. Therefore, the repair performance of patch with stacking sequence [90/90/90] is much better than others based on the comparisons of absorbed energy and delamination area. However, when the impactor penetrates a specific depth into the repaired specimens, the longitude layer provides additional strength to avoid the extension of delamination. Therefore, the repair performance of the patch consists of only longitude-orientation-fiber layers (i.e. stacking sequence of [0/0/0]), is better than that of the patch with the stacking sequence of $[0 / 90 / 0]$.

\subsection{Optimization of external patch repair technique}

In this section, an optimization of external patch repair technique has been performed using numerical simulation. As presented in previous section, patch configuration parameters, such as patch thickness and stacking sequence, was used to investigate their effect on the repair performance for damaged CFRP laminates. For the stacking sequence of repair patch, the layout design which only consists of latitude fiber layers, provides better enhanced impact-resistance than others. Furthermore, the repair performance is dramatically improved with the increase of patch thickness (number of layers). Nonetheless, the repair design with thick patches (more than 5 layers) is likely to cause singularities on the repaired structures. Thus, no more than 5 layers are proposed to use for the external patch repair for damaged CFRP laminates.

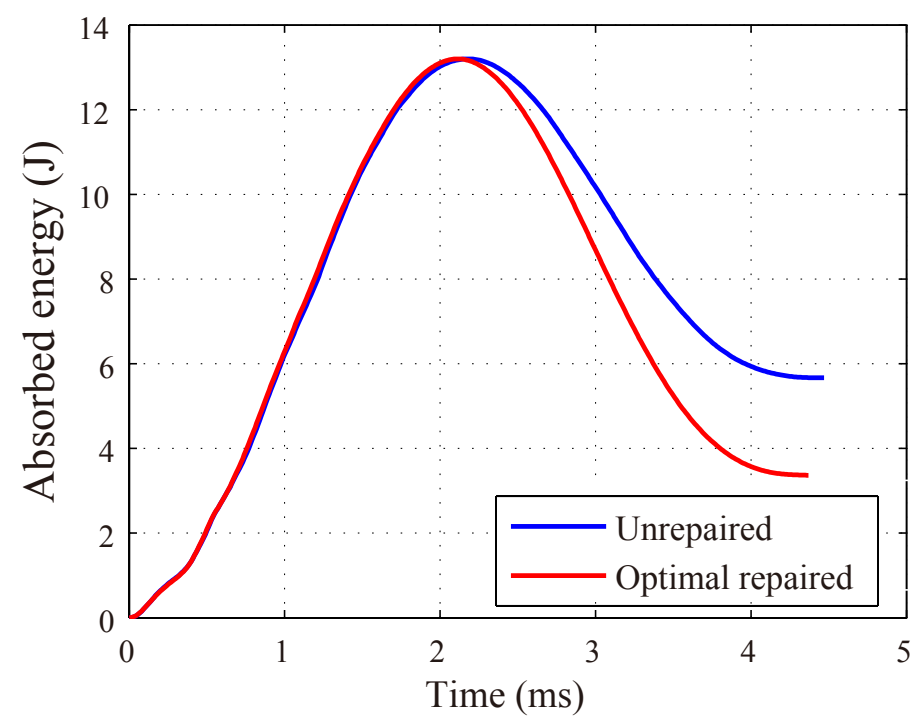

Figure 19: Predicted impact energy curves of unrepaired and repaired specimens with optimal patch design.

Additionally, in our former study [17], the effect of patch shape and size had been already discussed, and it was found that, circle patch with radius of $2.5 \mathrm{r}$ can provide an enhanced impactresistance than other designs in the terms of patch shape and size. Consequently, the design with 
a circle five-layer patch with radius of $2.5 \mathrm{r}$ and stacking sequence of $\left[(90)_{5}\right]$, is considered as the optimal solution. Numerical simulations of low-velocity impact tests are performed on both of the unrepaired and repaired specimens to evaluate the impact-resistance of optimal patch design.

The predicted impact energy curves of these two specimens (unrepaired and repaired specimens with optimal patch design) are depicted in Fig. 19. From Fig. 19, the values of absorbed energy are $5.67 \mathrm{~J}$ and $3.36 \mathrm{~J}$ for these two specimens, respectively. Therefore, we can conclude that, the optimal patch design improves the impact-resistance properties of damaged CFRP laminates by $40.7 \%$. Thus, the external patch repair technique using an appropriate patch configuration can be used to restore the impact-resistance of damaged CFRP laminates. Besides, the repair performance is affected by many other factors, e.g., the used adhesive, surface preparation of parent laminates. Extension of the work on this subject will necessitate to take into account the influence of these factors.

\section{Conclusions and perspectives}

In this study, different patch design configurations were used to repair the parent laminates with a damage hole. Experimental and numerical drop-weight tests were performed on the repaired specimens to investigate the influence of impact location and external patch design parameters on the low-velocity impact behaviors. The numerical prediction is in good agreement with the experimental measurements, it validates the proposed numerical simulation strategy.

To investigate the effect of impact location on the low-velocity impact behaviors, the relative distances between the damage hole and the impact point (center of parent laminates) was varied from $0 \mathrm{~mm}$ to $50 \mathrm{~mm}$. The simulation results show that, the increase of relative distance initially leads to decrease the absorbed energy, and then the absorbed energy stabilizes after the relative distance of $30 \mathrm{~mm}$. But, the delamination area suddenly increases with the increase of relative distance, and it also stabilizes at the relative distance of $20 \mathrm{~mm}$. It is attributed to the fact that, in the case of the relative distance fixed as $10 \mathrm{~mm}$, the impactor firstly contacts the patch boundary and it enables the delamination and debonding within the patch. When the impactor finally penetrates the repaired laminates, the intermediate velocity and energy are significantly reduced, so that a relatively smaller delamination surface is predicted on the repaired specimen. Moreover, when the relative distance reaches $20 \mathrm{~mm}$, the impactor directly contacts the parent plate with full initial velocity, which leads to the sudden increase of delamination area.

In addition, the effects of external patch parameters on the repair performance including patch thickness and stacking sequence, have been investigated using numerical simulations. Patches with different thicknesses, in which the number of layers is increased from 1 to 5 , were used to repair the damaged CFRP laminates. As patch thickness (number of layers) increasing, both absorbed energy and delamination area decrease with the same overall trend. Nevertheless, to ensure the static and dynamic stabilities of repaired structures, no more than 5 layers are proposed to compose the repair patch design. Numerical simulations of low-velocity impact tests were also performed on specimens repaired using patches with various stacking sequences. According to the simulation results, the patch which consists of only latitude-orientation-fiber layers, provided better impactresistance to the repaired laminates. Finally, an optimization design of the patch configuration was proposed based on the numerical simulations. By comparing results with unrepaired specimen, 
the proposed patch design significantly restores the impact-resistance of damaged laminates by 40.7\%. The promising results clearly indicate the robustness and effectiveness of the proposed simulation method.

Although the initial residual stresses were negligible in the numerical simulation of lowvelocity impact test, it is necessary to understand the effect of pre-loading due to the fixture loading (or applied pre-tension or pre-bending loads) on the impact response of repaired CFRP laminates. Furthermore, combining our previous study [17] with this one, the effect of various design parameters (i.e. patch shape, size, thickness, stacking sequence) on the repair performance has been analyzed individually. However, due to the complexity of the interaction between these parameters on the repair performance, the correlation of these design parameters should be taken into account during an optimization problem. Therefore, advanced structural optimization methods, such as surrogate-based optimization [41, 42] or topology optimization [43] techniques, having the capability to search the optimum repair patch design, could be considered to establish the correlation between the individual parameters.

\section{Acknowledgements}

Authors acknowledge the sponsorship and support from Natural Science Foundation of China (NSFC, U1833116), and the China Postdoctoral Science Foundation Funded Project (2016M60225 6 and 2018M642775). This study is also supported by Fundamental Research Funds of Zhengzhou University (F0001261), and Excellent Talented Teacher Project (1521321036).

\section{References}

[1] A. Baker, Joining and repair of aircraft composite structures, Composites engineering handbook(A 98-11526 01-24), New York, Marcel Dekker, Inc.(Materials Engineering). 11 (1997) 671-776.

[2] N. Li, M. B. Tahar, Z. Aboura, K. Khellil, A dynamic analysis approach for identifying the elastic properties of unstitched and stitched composite plates, Composite Structures 152 (2016) 959-968.

[3] L. Xia, D. Da, J. Yvonnet, Topology optimization for maximizing the fracture resistance of quasi-brittle composites, Computer Methods in Applied Mechanics and Engineering 332 (2018) 234-254.

[4] L. Xia, L. Zhang, Q. Xia, T. Shi, Stress-based topology optimization using bi-directional evolutionary structural optimization method, Computer Methods in Applied Mechanics and Engineering 333 (2018) 356-370.

[5] Y. Xu, H. Lu, T. Gao, W. Zhang, Predicting the low-velocity impact behavior of polycarbonate: Influence of thermal history during injection molding, International Journal of Impact Engineering 86 (2015) 265-273.

[6] Y. Xu, P. Zhang, H. Lu, W. Zhang, Hierarchically modeling the elastic properties of 2D needled carbon/carbon composites, Composite Structures 133 (2015) 148-156.

[7] M. Charalambides, R. Hardouin, A. Kinloch, F. Matthews, Adhesively-bonded repairs to fibre-composite materials I. Experimental, Composites Part A: Applied Science and Manufacturing 29 (11) (1998) 1371-1381.

[8] M. Charalambides, A. Kinloch, F. Matthews, Adhesively-bonded repairs to fibre-composite materials II. Finite element modelling, Composites Part A: Applied Science and Manufacturing 29 (11) (1998) 1383-1396.

[9] Z. P. Marioli-Riga, X. Dionissios, Repairability and cost analysis criteria for typical composite patch repairs, Facta universitatis-series: Mechanics, Automatic Control and Robotics 3 (14) (2003) 951-962.

[10] X. Cheng, X. Du, J. Zhang, J. Zhang, X. Guo, J. Bao, Effects of stacking sequence and rotation angle of patch on low velocity impact performance of scarf repaired laminates, Composites Part B: Engineering 133 (2018) $78-85$.

[11] G. G. Triantafyllou, T. C. Rousakis, A. I. Karabinis, Effect of patch repair and strengthening with EBR and NSM CFRP laminates for RC beams with low, medium and heavy corrosion, Composites Part B: Engineering 133 (2018) 101-111. 
[12] V. S. Balakrishnan, H. Seidlitz, Potential repair techniques for automotive composites: A review, Composites Part B: Engineering 145 (2018) 28-38.

[13] F. Hu, C. Soutis, Strength prediction of patch-repaired CFRP laminates loaded in compression, Composites Science and Technology 60 (7) (2000) 1103-1114.

[14] P. Papanikos, K. Tserpes, G. Labeas, S. Pantelakis, Progressive damage modelling of bonded composite repairs, Theoretical and Applied Fracture Mechanics 43 (2) (2005) 189-198.

[15] J. J. Andrew, S. M. Srinivasan, A. Arockiarajan, The role of adhesively bonded super hybrid external patches on the impact and post-impact response of repaired glass/epoxy composite laminates, Composite Structures 184 (2018) 848-859.

[16] S. Coelho, P. Reis, J. Ferreira, A. Pereira, Effects of external patch configuration on repaired composite laminates subjected to multi-impacts, Composite Structures 168 (2017) 259-265.

[17] Y. Tie, Y. Hou, C. Li, X. Zhou, T. Sapanathan, M. Rachik, An insight into the low-velocity impact behavior of patch-repaired CFRP laminates using numerical and experimental approaches, Composite Structures 190 (2018) 179-188.

[18] O. Balcı, O. Çoban, M. Ö. Bora, E. Akagündüz, E. B. Yalçin, Experimental investigation of single and repeated impacts for repaired honeycomb sandwich structures, Materials Science and Engineering: A 682 (2017) 23 -30.

[19] M. Richardson, M. Wisheart, Review of low-velocity impact properties of composite materials, Composites Part A: Applied Science and Manufacturing 27 (12) (1996) 1123-1131.

[20] C. Lopes, P. Camanho, Z. Gürdal, P. Maimí, E. González, Low-velocity impact damage on dispersed stacking sequence laminates. Part II: Numerical simulations, Composites Science and Technology 69 (7-8) (2009) 937947.

[21] A. Soto, E. González, P. Maimí, F. M. De La Escalera, J. S. De Aja, E. Alvarez, Low velocity impact and compression after impact simulation of thin ply laminates, Composites Part A: Applied Science and Manufacturing 109 (2018) 413-427.

[22] E. González, P. Maimí, J. S. De Aja, P. Cruz, P. Camanho, Effects of interply hybridization on the damage resistance and tolerance of composite laminates, Composite Structures 108 (2014) 319-331.

[23] A. Jefferson, V. Arumugam, C. Santulli, A. Jennifers, M. Poorani, Failure modes of GFRP after multiple impacts determined by acoustic emission and digital image correlation, Journal of Engineering and Technology (JET) 6 (2) (2015) 29-51.

[24] J. J. Andrew, V. Arumugam, K. Saravanakumar, H. N. Dhakal, C. Santulli, Compression after impact strength of repaired GFRP composite laminates under repeated impact loading, Composite Structures 133 (2015) 911-920.

[25] P. Cheng, X.-J. Gong, D. Hearn, S. Aivazzadeh, Tensile behaviour of patch-repaired CFRP laminates, Composite structures 93 (2) (2011) 582-589.

[26] X.-J. Gong, P. Cheng, S. Aivazzadeh, X. Xiao, Design and optimization of bonded patch repairs of laminated composite structures, Composite Structures 123 (2015) 292-300.

[27] M. Ramji, R. Srilakshmi, M. B. Prakash, Towards optimization of patch shape on the performance of bonded composite repair using FEM, Composites Part B: Engineering 45 (1) (2013) 710-720.

[28] Y. Xu, Q. Zhang, W. Zhang, P. Zhang, Optimization of injection molding process parameters to improve the mechanical performance of polymer product against impact, The International Journal of Advanced Manufacturing Technology 76 (9-12) (2015) 2199-2208.

[29] Y. Xu, H. Lu, T. Gao, W. Zhang, Processing-induced inhomogeneity of yield stress in polycarbonate product and its influence on the impact behavior, Polymers 8 (3) (2016) 72.

[30] H. Singh, K. K. Namala, P. Mahajan, A damage evolution study of E-glass/epoxy composite under low velocity impact, Composites Part B: Engineering 76 (2015) 235-248.

[31] L. M. Fernández-Cañadas, I. Iváñez, S. Sanchez-Saez, Influence of the cohesive law shape on the composite adhesively-bonded patch repair behaviour, Composites Part B: Engineering 91 (2016) 414-421.

[32] D.-H. Kim, K.-H. Jung, I.-G. Lee, H.-J. Kim, H.-S. Kim, Three-dimensional progressive failure modeling of glass fiber reinforced thermoplastic composites for impact simulation, Composite Structures 176 (2017) 757767.

[33] ASTM D7136/D7136M-07 standard test method for measuring the damage resistance of a fiber-reinforced polymer matrix composite to a drop-weight impact event, 2003. 
[34] Hibbitt, Karlsson, Sorensen, ABAQUS/Explicit: user's manual, Vol. 1, Hibbitt, Karlsson and Sorenson Incorporated, 2001.

[35] Z. HASHI, Failure criteria for unidirectional fiber composite, Journal of Applied Mechanics 47 (1980) 3292334.

[36] K. C. Warren, R. A. Lopez-Anido, S. S. Vel, H. H. Bayraktar, Progressive failure analysis of three-dimensional woven carbon composites in single-bolt, double-shear bearing, Composites Part B: Engineering 84 (2016) 266276.

[37] J.-F. Chen, E. V. Morozov, K. Shankar, Simulating progressive failure of composite laminates including in-ply and delamination damage effects, Composites Part A: Applied Science and Manufacturing 61 (2014) 185-200.

[38] L. Jia, L. Yu, K. Zhang, M. Li, Y. Jia, B. Blackman, J. Dear, Combined modelling and experimental studies of failure in thick laminates under out-of-plane shear, Composites Part B: Engineering 105 (2016) 8-22.

[39] F. Aymerich, F. Dore, P. Priolo, Prediction of impact-induced delamination in cross-ply composite laminates using cohesive interface elements, Composites science and technology 68 (12) (2008) 2383-2390.

[40] M. De Moura, J. Gonçalves, J. Chousal, R. Campilho, Cohesive and continuum mixed-mode damage models applied to the simulation of the mechanical behaviour of bonded joints, International Journal of Adhesion and Adhesives 28 (8) (2008) 419-426.

[41] Y. Hou, T. Sapanathan, A. Dumon, P. Culière, M. Rachik, A novel development of bi-level reduced surrogate model to predict ductile fracture behaviors, Engineering Fracture Mechanics 188 (2018) 232-249.

[42] L. Meng, P. Breitkopf, G. Le Quilliec, B. Raghavan, P. Villon, Nonlinear shape-manifold learning approach: concepts, tools and applications, Archives of Computational Methods in Engineering 25 (1) (2018) 1-21.

[43] Z. Wu, L. Xia, S. Wang, T. Shi, Topology optimization of hierarchical lattice structures with substructuring, Computer Methods in Applied Mechanics and Engineering 345 (2019) 602-617. 